\title{
Atrial septal aneurysm in Sub-Saharan Africa: From an asymptomatic incidental echocardiographic finding to a potential cause of cardio embolic stroke
}

\author{
Raphael Anakwue, ${ }^{1}$ Angel-Mary Anakwue ${ }^{2}$ \\ ${ }^{1}$ Departments of Medicine, Pharmacology/Therapeutics; ${ }^{2}$ Department of Radiography and Radiological \\ Sciences, University of Nigeria, Enugu Campus, Enugu, Nigeria
}

\begin{abstract}
Atrial Septal Aneurysm (ASA) is an abnormality of the interatrial septum that has continued to generate interest because of its rarity, asymptomatic presentation and possibility to cause cardioembolic stroke. There are many published accounts of atrial septal aneurysm in USA, Europe and Asia but very few published reports from sub-Saharan Africa. Our first case is a 48 years old
\end{abstract}

Correspondence: Angel-Mary Anakwue. Department of Radiography and Radiological Sciences, University of Nigeria Enugu Campus, Enugu, Nigeria.

Tel.: +234.8035495528

E-mail: angel-mary.anakwue@unn.edu.ng

Key words: Atrial septal aneurysm; stroke; echocardiography; subSaharan Africa.

Acknowledgement: We wish to acknowledge the staff and management of Cosmas and Damian Medical Centre Enugu, a specialized cardiac care center, where the patients were primarily diagnosed and managed.

Contributions: RA conceived the research; AC acquired the echocardiographic images; RA and AC wrote the manuscript; All authors approved the manuscript.

Conflict of interest: The authors declare no conflict of interest.

Ethics approval and consent to participate: Ethical approval was obtained from the Ethics Committee of the State Ministry of Health.

Consent for publication: The patients' written informed consent was obtained for the publication of these case reports as well as the accompanying images before this publication.

Availability of data and materials: All data generated during this study are included in this published article.

Received for publication: 17 August 2020.

Revision received: 14 December 2020.

Accepted for publication: 14 December 2020.

This work is licensed under a Creative Commons Attribution NonCommercial 4.0 License (CC BY-NC 4.0).

C Copyright: the Author(s), 2021

Licensee PAGEPress, Italy

Annals of Clinical and Biomedical Research 2021;2:101

doi:10.4081/acbr.2021.101 female patient with type 1 ASA presented as an incidental finding during echocardiographic investigative procedures for other cardiac diagnosis. The second case is a 58 years old female with type 2L ASA, who presented with transient loss of consciousness lasting for 5 minutes. Our third case is a 25 years old male with type 5 ASA with heart failure who presented with exertional dyspnoea for 3 years. In this presentation, we ask questions about the reason for rare presentations and or publications of atrial septal aneurysm from Africa. We also re-examined the different associations of ASA as well as clinical presentations. ASA is an often asymptomatic but treatable cause of cardiovascular disease that includes cardioembolic stroke. A high index of suspicion is required to make the diagnosis during routine trans thoracic echocardiography and the availability of transesophageal echocardiography will definitely improve diagnosis and management of cases in sub-Saharan Africa.

\section{Introduction}

Atrial Septal Aneurysm (ASA) is a saccular deformity of the atrial septum. The American Society of Echocardiography guidelines defines ASA as an excursion or maximal deviation of Interatrial Septum (IAS) of $10 \mathrm{~mm}$ from the plane of the atrial septum into the right atrium (RA) or left atrium (LA) or a combined excursion right and left of $15 \mathrm{~mm} .{ }^{1}$ This appears to be the most widely accepted definition. Some authorities have put the excursion to more than $15 \mathrm{~mm}$, citing that septal excursion less than 15 $\mathrm{mm}$ should be referred to as redundant atrial septum. ${ }^{2}$ The deviation should be measured from the plane of the remaining part of septum and should be at least $10 \mathrm{~mm}$ in width. ${ }^{3}$

In the largest series of cases of ASA diagnosed by TEE, Pearson and co-workers 4 considered a septum aneurysmal when it had an excursion $>10 \mathrm{~mm}$ into either the left or right atrium or a sum of the total excursion into the left or right atrium $>10 \mathrm{~mm}$, with a base width $\geq 15 \mathrm{~mm} .4,5$ Other authors define ASA as a thin localized outpouching of the middle portion of the atrial septum, but not the entire septum, protruding at least $10 \mathrm{~mm}$ outside the plane of the atrial septum. ${ }^{6}$ It should be stated that not all bulges of IAS are ASA. For instance, the IAS bulges to the right in severe mitral stenosis and similarly, IAS bulges to the left in severe pulmonary hypertension with tricuspid regurgitation. But none of these will produce protrusion of the IAS or part of it from atrial septal plane to diagnose ASA. ${ }^{7}$ In rare situations with chronically elevated atrial pressure as in mitral stenosis there could be ASA but this is likely due to possible inherent congenital abnormality.-There could be movement of the atrial aneurysm depending on the relative pressures of the two atria. ${ }^{3}$ There is a displacement towards right atrium due to relatively higher pressure of the left atrium throughout the cardiac cycle. During inspiration, there is increased 
filling of the right side of heart due to increased venous return. This may result in transient mild elevation of right atrial pressure and transient movement of the aneurysm towards left atrium. Right ventricular hypertrophy, tricuspid regurgitation and tricuspid stenosis and other conditions that increase the right atrial pressure can displace atrial aneurysm to the left particularly during some part of the cardiac cycle. ${ }^{4}$

Defects in the IAS may be associated with ASA and so an account of the formation of the IAS would be important in appreciating some of the clinical presentations of ASA. A thin membranous septum primum divides the fetal atria early in embryonic life and overlaps the thicker septum secundum, which contains an opening called foramen ovale that occupies its middle third. The foramen ovale is guarded by a thin membrane, the foraminal flap, which flickers into the body of the left atrium. ${ }^{8}$ The septum primum effectively closes the foramen ovale in early neonatal life as left atrial pressure exceeds right atrial pressure and the septum primum adheres to the septum secundum. ${ }^{9}$

The atrial septum has three components: the septum primum, septum secundum, and Atrioventricular (AV) canal septum and the sinus venosus though not a component of the true atrial septum is an adjacent structure (separates the right pulmonary veins from the superior vena cava and posterior right atrium ) through which an atrial communication can occur. ${ }^{10,11}$

The foramen ovale and its flap-like valve between the right and left atrium are important components of the fetal circulation. In the developing fetus, oxygenated blood from the umbilical vein enters the right atrium via the inferior vena cava and is shunted into the left atrium, circumventing the noninflated lungs. After birth, a relative increase in left atrial pressure closes the flap, and adhesions frequently result in a structurally intact atrial septum. However, in approximately 25 percent of adults, the foramen ovale remains patent and acts as a potential interatrial shunt and may produce small right to left shunt. ${ }^{10}$

Olivares-Reyes et al. proposed a new classification of ASA that is complete, simple and practical. Type $1 \mathrm{R}$ if the bulging is in the right atrium only, type $2 \mathrm{~L}$ if the bulging is in the left atrium only, type $3 \mathrm{RL}$ if the major excursion bulges to the right atrium and the lesser excursion bulges toward the left, type 4LR if the maximal excursion of the ASA is toward the left atrium with a lesser excursion toward the right atrium, type 5 if the ASA movement is bidirectional and equidistant to both atria during the cardiorespiratory cycle. ${ }^{11}$

The prevalence of ASA in adults varies and depends on the era: pre Trans Esophageal Echocardiography (TEE) and post TEE. Transthoracic Echocardiographic (TTE) studies estimate the prevalence to be between $0.08 \%$ and $1.2 \%{ }^{11}$ But the advent of trans esophageal echocardiographic has increased the diagnosis and the prevalence to between $2 \%$ and $5 \%{ }^{11}$ The excursion of the atrial septum can be documented using 2D imaging, as well as $\mathrm{M}$-mode assessment when the M-mode cursor can be aligned perpendicular to the plane of the IAS. This can be done in the subcostal four-chamber views on TTE, in the bicaval views on TEE, and in the septal long-axis views on Intra cardiac echocardiography. ${ }^{11}$

The prevalence of ASA in Africa and Nigeria is unknown but appears to be rare considering the few reports of atrial septal aneurysm from Africa. We searched PubMed, Google scholar, Medline and African Journal Online (AJOL) for articles on over a period of 30 years. The search was from January 1990 to January 2020, a 30year period. Search words included "atrial septal aneurysm", "atrial septal defect", "Patent foramen ovale" with "Africa", "echocardiography". Figure 1 depicts the selection process and the outcome.

In a report of twenty-two years of repair of 129 cases of atrial septal defects in Ghana there was no mention of ASA among the patients that had repairs. Secundum ASDs were 104 (80.6\%), primum ASDs were $14(10.9 \%)$, sinus venosus type were $6(4.7 \%)$ and common atrium were $5(3.9 \%) .{ }^{12}$

There are three reports of ASA from South Africa. James Ker reported a case of an unusual atrial septal aneurysm which presented as a bulging of the entire atrial septum into the left atrium as ventricular systole progressed. There were no other associated cardiac abnormalities.

The second case was also reported by James Ker. The 55 years old Caucasian presented with exertional dyspnea and echocardiography showed interatrial septal aneurysm, which was bulging into the left atrium. There was a surprising finding of pulmonary embolism secondary to cardiac thrombi ostensibly originating from the ASA. ${ }^{13}$

The third report involved two cases. The first patient, a 50 years old male with diabetes mellitus type 2 and a history of multiple transient ischaemic episodes. Transoesophageal echocardiography (TEE)showed a hyper-mobile ASA and a thick septum secundum. There was a right-to-left shunt during Valsalva contrast echocardiography. ${ }^{14}$

30 titles/abstracts on atrial septal aneurysm, atrial septal defect, Patent foramen ovale with Africa, echocardiography retrieved
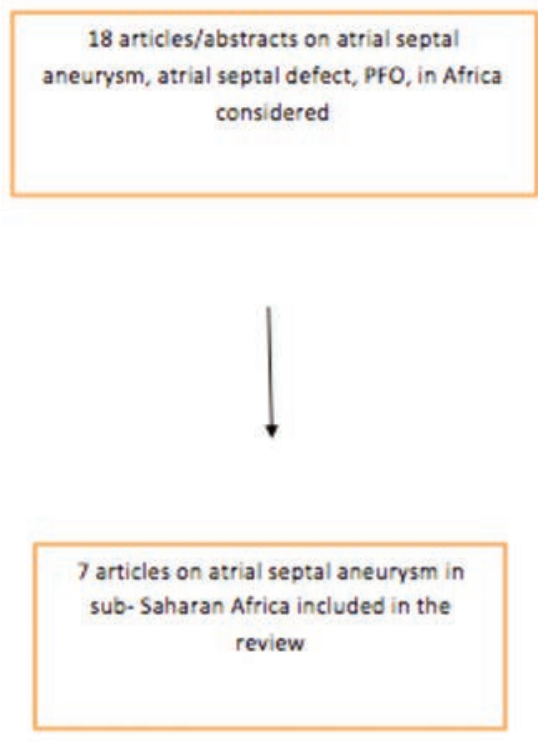

Figure 1. Article selection process. 
The second patient was a 39 years old male who had a history of repeated episodes of transient hemiparesis. TEE showed a septal aneurysm and PFO tunnel of $5 \mathrm{~mm}$ in length with a shunt. The thick septum secundum was measured at $12 \mathrm{~mm}$ in length. ${ }^{14}$

There is a report from Kenya involving a baby, cyanosed at birth with systemic desaturation. The two-dimensional echocardiograms showed tricuspid atresia with hypoplastic right ventricle, large secundum atrial septal defect, and highly mobile gigantic aneurysms of the atrial septum obstructing the inflow of the mitral valve and entering the left ventricle in diastole. ${ }^{15}$

There are also three reports from Nigeria. One is a case report of 80 years old woman with ASA who presented with cardiac failure in Norther Nigeria. ${ }^{16}$ The other is a 37 years old woman with a recurrent atypical chest pain of one-year duration. She was found to have a congenital atrial septal aneurysm on evaluation. The echocardiographic images mimicked a left sided cor triatriatum sinister. She had no other symptoms and had no comorbidities. There was no audible murmur. ${ }^{17}$ The third is a preterm baby who had poor fetal movements and bradyarrhythmia in utero and had an emergency caesarian section at 35weeks with Apgar score of 3 . Trans thoracic echocardiogram done on the $12^{\text {th }}$ day of life revealed ASA protruding from the midline of the atrial septum to the left atrium throughout the cardio-respiratory cycle (a type $2 \mathrm{~L}$ ASA). ${ }^{18}$

\section{Case Reports}

We report three cases of ASA seen in a specialist cardiology center in Enugu. These three case reports demonstrate the three possible clinical presentations of ASA firstly as an incidental finding during echocardiographic investigative procedures for other cardiac diagnosis, secondly as a case of heart failure associated with atrial septal defect following abnormal circulatory conditions resulting in systolic and or diastolic heart failure and thirdly transient ischaemic attack and stroke due to arrhythmia and cardioembolism.

The patients' consent was obtained before this publication.

\section{Case \#1}

A 48 years old female patient presented with chest pain and history of hypertension for 8 years. The pain was central and nonradiating and has no relationship with exercise or rest. No breathlessness, cough or leg swelling. Patient is not diabetic. Blood pressure was $180 / 98 \mathrm{mmHg}$. Pulse is regular at 88 beats per minute. Apex beat displaced to $5^{\text {th }}$ left intercoastal space lateral to midclavicular line. Heart sounds are normal, no murmurs. Lipid profile was deranged with increased total cholesterol and LDL cholesterol. Serum electrolytes, urea and creatinine were normal. ECG was normal. Echocardiography report showed atrial septal aneurysm involving part of the atrial septum. The septal movement is type $1 \mathrm{R}$ as the septum bulges by $18 \mathrm{~mm}$ into the right atrium only. No PFO or atrial septal defect in this trans thoracic echo. No atrial septal or ventricular septal defect could be demonstrated. No chamber dilatation. No intracardiac clots. The valves are normal. There is bi ventricular diastolic dysfunction. Ventricular systolic function is normal. The pericardium was normal (Figure 2). Patient was continued on antihypertensive drugs, namely amlodipine $10 \mathrm{mg}$ daily, telmisartan $80 \mathrm{mg}$ daily, chlorthalidone $1.25 \mathrm{mg}$ daily, atorvastatin 2omg daily, low dose aspirin $75 \mathrm{mg}$ daily. Her blood pressure during last assessment was $120 / 80 \mathrm{mmHg}$. Chest pain has stopped and patient is stable.

\section{Case \#2}

A 58 years old female presented with transient loss of consciousness lasting for 5 minutes. This repeated twice in the previous 6 months. She also has palpitations but no chest pain. Clinical examination showed an irregular pulse at 120 beats per minute, pulse deficit of $24 \mathrm{bpm}$, and $132 / 76 \mathrm{mmHg}$ blood pressure. The heart sounds are normal, no murmurs. Central nervous system examination and other system examination normal. Full blood count, serum electrolyte, urea and creatinine, lipid profile are normal. ECG showed atrial fibrillation with a ventricular rate of 94 /min, normal QRS, ST and T wave. Brain CT showed normal findings, no hemorrhagic and no ischaemic foci. Transthoracic echocardiography reveals normal-size chambers, valves, no intracardiac clots, vegetation or mass. There is a class 2L ASA but no shunt demonstrable (Figure 3). No atrial or ventricular septal defect. The diagnosis was that of Cardioembolic stroke secondary to intracardiac thrombosis. Patient was placed on Metoprolol XL $50 \mathrm{mg}$ daily and aspirin $75 \mathrm{mg}$ daily. He is currently in stable health.

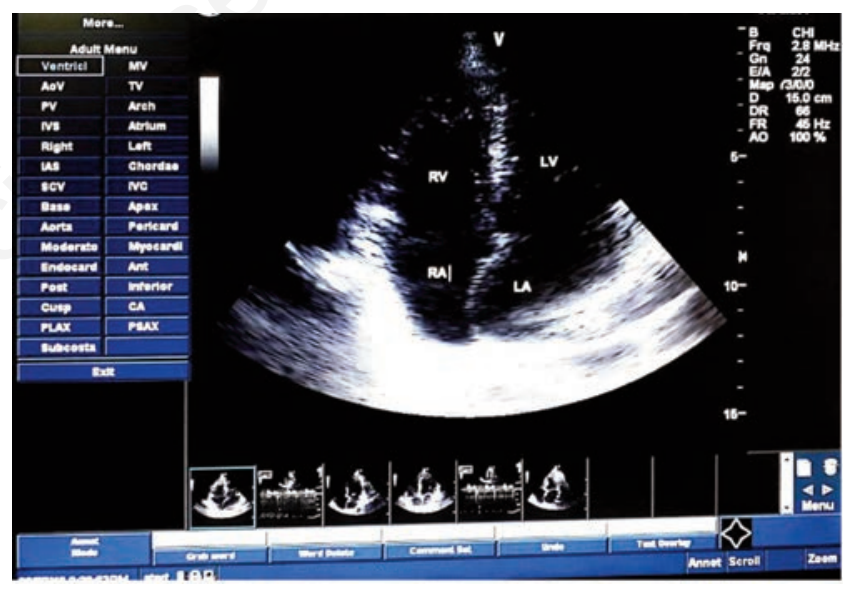

Figure 2. Type 1R atrial septal aneurysm in case 1.

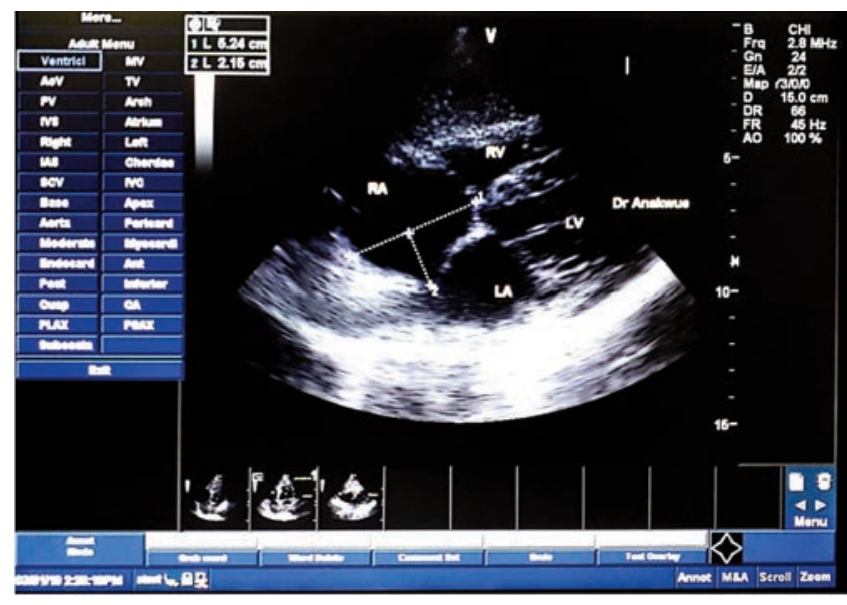

Figure 3. Type 1L atrial septal aneurysm in case 2 . 


\section{Case \#3}

A 25 years old male university student presented with exertional dyspnoea for 3 years. Illness started with an insidious onset of reduced effort tolerance with progressive exertional dyspnoea, orthopnea, paroxysmal nocturnal dyspnoea, fatigue and cough in the later stages. He had cough with clear mucoid expectoration but not bloody. He also reported intermittent palpitations, central chest pain involving the left side with no associated radiation, no inducing or ameliorating position, activity and with no relation to food intake. There was no abdominal swelling, abdominal pain, jaundice or change in urine volume or color. There was no history of fainting or weakness on any side of the body. No prior diagnosis of hypertension, diabetes mellitus, chronic lung disease or stroke. No history of recurrent sore throats in the past. He had been on oral medication prescribed prior to referral: Spironolactone $(25 \mathrm{mg}$ daily), Digoxin ( $0.25 \mathrm{mg}$ daily) and Lisinopril ( $25 \mathrm{mg}$ daily). There was no reported history of drug allergy or personal atopy. No history of substance abuse. No significant alcohol, smoking or herbal intake. No family history of stroke, heart disease or sudden death. On examination, not in any distress, afebrile, not pale, acyanosed, anicteric, no digital clubbing, no peripheral lymphadenopathy and no peripheral edema. Cardiovascular system examination: pulse was $72 \mathrm{bpm}$, normal volume and regular. Blood pressure was $110 / 68 \mathrm{mmHg}$. Jugular venous pulsation was not elevated. Apical impulse was at the $6^{\text {th }}$ left intercoastal space, anterior axillary line, non-heaving, non-tapping. First, second and third heart sounds were heard with an apical grade 3/6 pansystolic murmur. Respiratory system examination: RR was $18 \mathrm{bpm}$, regular and had nil chest deformity or scar. Vesicular breath sounds heard.

Systemic examination was uneventful. The diagnosis was valvular heart disease with heart failure secondary to rheumatic heart disease. Initial treatment was with Tab Frusemide $40 \mathrm{mg}$ bd, Tab Spironolactone $25 \mathrm{mg}$ daily, Tab Lisinopril $2.5 \mathrm{mg}$ daily. Echocardiographic report showed atrial septal aneurysm grade 5 with ASD (Figure 4) measuring about $31 \mathrm{~mm}$ with left to right shunt across the septum. No intracardiac clots or vegetation at time of examination. Multivalvular heart disease with mitral and tricuspid valvular regurgitation. Right ventricular hypertrophy. Bi ventricular systolic dysfunction. Biventricular diastolic dysfunction and pulmonary hypertension. Rest ECG showed heart rate of 101/min, sinus rhythm, left atrial abnormality, normal QRS axis, Prolonged PR interval, Normal QRS interval, Normal QT segment. Right ventricular hypertrophy.

FBC Hb- $9.2 \mathrm{~g} / \mathrm{dl}$, WBC $4.96 \times 10^{9}$, Neut $71 \%$, Lymph $14 \%$, Mono $7 \%$, Eosin $6 \%$, Baso- $<1 \%$.

Serum electrolyte, urea and creatinine result: $\mathrm{Na} 138 \mathrm{mmol} / \mathrm{L}$, K $4.6 \mathrm{mmol} / \mathrm{L}$, Bicarbonate $21 \mathrm{mmol} / \mathrm{L}, \mathrm{Cl} 103 \mathrm{mmol} / \mathrm{L}$, Urea 2.7 $\mathrm{mmol} / \mathrm{L}$, Creatinine $88 \mathrm{mmol} / \mathrm{L}$.

Lipid Profile result showed: Total Cho $7.1 \mathrm{mmol} / \mathrm{L}$, HDL-C $1.1 \mathrm{mmol} / \mathrm{L}$, LDL C $5.5 \mathrm{mmol} / \mathrm{L}$, VLDL C $0.5 \mathrm{mmol} / \mathrm{L}$, Triglyceride $1.0 \mathrm{mmol} / \mathrm{L}$.

Treatment was revised to: Tab Frusemide $40 \mathrm{mg}$ daily, Tab Spironolactone $25 \mathrm{mg}$ daily, Tab Lisinopril $2.5 \mathrm{mg}$ daily, Tab Atorvastatin $20 \mathrm{mg}$ daily, Tab Slidenafil $25 \mathrm{mg}$ daily, Tab levofloxacin $500 \mathrm{mg}$ bd.

Patient was worked up for surgery. He had an ASD repair with Tricuspid valve annuloplasty in University of Nigeria Teaching hospital, Enugu. Immediate post-operative echocardiography showed successful closure of the ASD and stabilization of the atrial septal septum (Figure 5).

Post-operative status was satisfactory. He is presently on dual antiplatelet therapy with Aspirin/Clopidogrel and reported marked improvement in effort tolerance.

\section{Discussion}

It is not clear why there are so few published cases of atrial septal aneurysm from sub-Saharan Africa. Rodriguez et al. had alluded to race-ethnic differences among patients with PFO, atrium and atrial septal abnormalities in USA. ${ }^{19}$ They reported that though the frequency of PFO did not vary among race-ethnic groups, a large PFO and right atrial anatomy favoring paradoxical embolization were significantly more prevalent among whites and Hispanics compared with blacks in USA.

Abdul-Majeed Salmasi et al. ${ }^{20}$ retrospectively studied 887 consecutive referrals to a General Cardiology and Hypertension clinics in USA and documented that atrial septal aneurysm was detected in 70 participants $(7.9 \%)$ and PFO in $18(2 \%)$. Atrial septal aneurysm, PFO, or their combination was detected most frequently in $15 \%$ of the Afro-Caribbean followed by $12 \%$ of the Caucasian patients and least in $3.7 \%$ of the Indo-Asian patients. In the absence of more published reports from Sub Saharan Africa, it is difficult to make any comparison between prevalence in blacks and Caucasians. What is certain is that there are so many published reports of ASA among Caucasians than blacks worldwide. ${ }^{21,22}$

Factors that may have contributed to few cases and sparse reporting of ASA among people in Sub- Saharan African may include unavailability of basic investigative tools like echocardiography as well as experts including cardiologists and echocardiographer technicians. Even when echocardiograhy machine is provided the probe, software and expertise for TEE may not be avail-
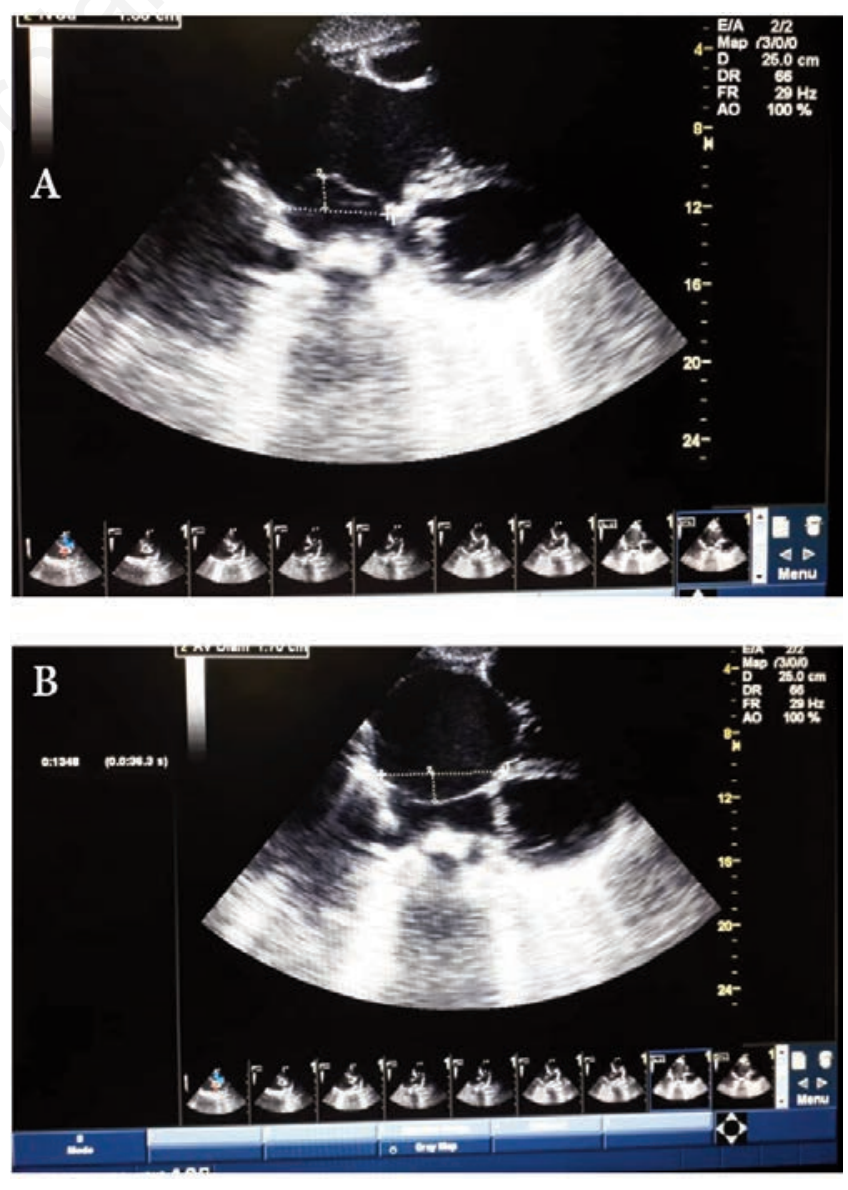

Figure 4. A) Type 4LR atrial septal aneurysm; B) Type 4LR atrial septal aneurysm (TTE). 
able. TEE has been shown to be more sensitive in diagnosing ASA than TTE. TEE is superior over TTE to diagnose ASA because it is more consistent in visualization of the interatrial septum. ${ }^{23}$ Mügge et al. had reported that $47 \%$ of ASA was missed with TTE. ${ }^{23}$

\section{Atrial septal aneurysm and associated cardiac abnor- malities}

ASA may occur in isolation or may be associated with other abnormalities. The commonest association is PFO. PFO represents failure of the primum and secundum septa to fuse and occurs in 20$25 \%$ of the population. ${ }^{1}$

As we have alluded earlier on in this article, after birth a relative increase in left atrial pressure closes the flap, and adhesions frequently result in a structurally intact atrial septum but that in a significant percentage of persons the foramen ovale remains patent and acts as a potential interatrial shunt which may produce small right to left shunt. ${ }^{10}$ In adults the IAS appears structurally intact but some left to right shunting can be demonstrated by either contrast or colour flow imaging. ${ }^{10}$

PFO has been associated with ASA in $50-75 \%$ of cases ${ }^{21}$ and is demonstrable by contrast or Doppler imaging where shunting of blood left to right $0 \mathrm{r}$ from right to left. Increased prevalence of cryptogenic stroke and other embolic events are also seen in persons with ASA and PFO. ${ }^{24}$

ASA with PFO has also been associated with platypnoea-orthodeoxia syndrome and with higher incidence of migraine with aura. ${ }^{25}$ The former is said to caused by preferential flow of blood from inferior vena cava through PFO and this leads to oxygen desaturation in upright position being relieved by supine position. ${ }^{7}$ The latter has no known etiology.

ASD is another cardiac abnormality associated with ASA. Differentiating a large ASD from a PFO is easy whether by TTE or TEE, but it becomes difficult if one is dealing with a small ASD. ${ }^{32}$ However a small ASD is characterized by a continuous interatrial shunting throughout the cardiac cycle but there is intermittent right to left shunting provoked by Valsalva maneuver in patients with PFO. ${ }^{26}$ Therefore, the differentiation between PFO and a small ASD is based on color Doppler TEE demonstrating a continuous interatrial shunting throughout the cardiac cycle in patients with ASD or an intermittent right-to-left shunting provoked by Valsalva maneuver in patients with PFO. ${ }^{21,26}$ ASD is more commonly found in cases where the ASA involves the entire septum than in cases where it is only the fossa ovalis that is affected. ${ }^{26}$ Mitral valve prolapse is also associated with ASA. It is thought that the redundancy of the atrial septum and the mitral and/or tricuspid valve may be commonly related to inherent deficiency in the connective tissue. Another type of cardiac abnormality often associated with ASA is mitral valve prolapse. ${ }^{27}$ It has been suggested that the redundancy of the atrial septum and the mitral (and/or tricuspid) valve may be secondary to a similar inherent deficiency in the connective tissue. ${ }^{28}$ Other associations are atrial septal defect: valvular regurgitations, marfans syndrome, sinus of valsalva aneurysm and aortic dissection. . $^{21,26,29,30}$ Supraventricular arrhythmias Cerebrovascular Events (CVE) of embolic origin, including Transient Ischemic Attacks (TIA) and Cerebrovascular Accidents (CVA). ${ }^{21,26,31}$

Yetkin et al. ${ }^{32}$ investigated the prevalence and characteristics of ASA in a relatively large patient population including 16570 adult patients undergoing Transthoracic Echocardiography (TTE). Prevalence of ASA was documented in $2.4 \%$ of patients with a female dominance $(72 \%)$. They demonstrated that valvular regurgitations, and supraventricular arrhythmias were the most often accompanying pathologies to ASA. In another study including 15234 patients recently published by Jatav et al., similar findings were observed in terms of prevalence and associations. ${ }^{33}$

\section{Atrial septal aneurysm: clinical presentations}

ASA presents mainly as an asymptomatic incidental finding when echocardiography is done for other indications as in case report one. ${ }^{1}$ Atrial septal aneurysms are most commonly detected by transesophageal echocardiogram. Patients with ASA should be evaluated for presence of thrombus. However, when an incidental atrial septal aneurysm is well visualized by transthoracic echocardiogram, additional imaging with a transesophageal echocardiogram is not needed. ${ }^{34}$ Uncomplicated and isolated ASA requires no specific treatment other than follow-up and in some cases antiplatelet therapy. ${ }^{34}$ When atrial septal aneurysm is identified incidentally, no other intervention is needed except there are other abnormalities. ${ }^{34}$ Antiplatelet therapy is recommended for patients with cryptogenic stroke and an isolated atrial septal aneurysm. In patients with an atrial septal aneurysm and recurrent stroke while taking antiplatelet therapy, anticoagulant therapy is recommended

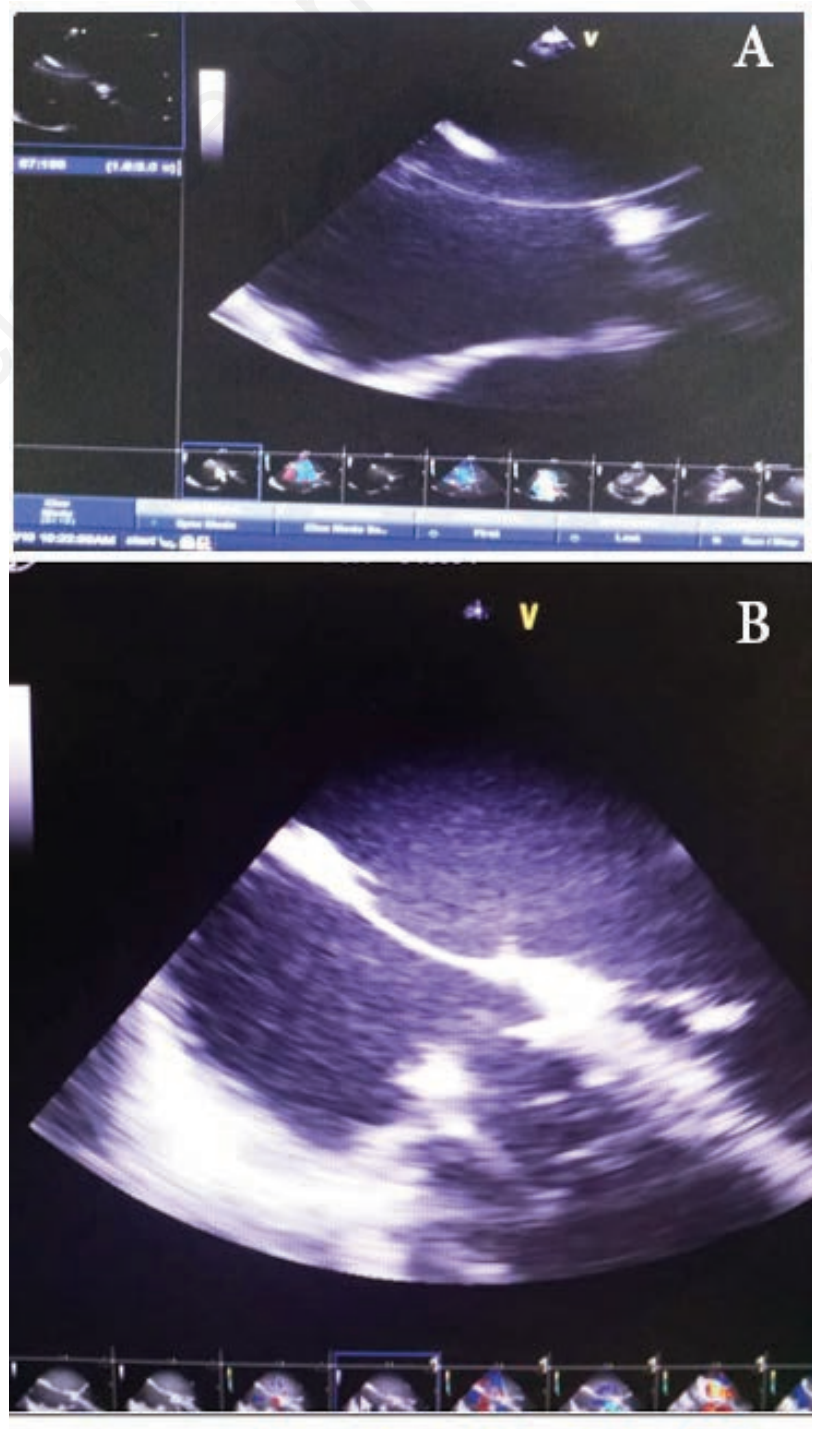

Figure 5. A) Atrial septal defect in a case of atrial septal aneurysm, before repair; B) Atrial septal defect in a case of atrial septal aneurysm after repair. 
if no other cause of stroke is identified. ${ }^{35}$

Rarely, surgical excision of an atrial septal aneurysm and defect closure is considered in patients in whom antiplatelet or warfarin therapy fails to prevent stroke recurrence or in patients with a large left-to-right shunt causing right heart enlargement. Percutaneous device closure is rarely performed in patients with atrial septal aneurysms, because a large device is required to plicate the atrial septal aneurysm and close multiple fenestrations. ${ }^{36}$

Interatrial septal aneurysm can act as an arrhythmic focus, generating focal atrial tachycardias which could lead to thromboembolism. The mechanism of increased prevalence of atrial tachyarrhythmia in ASA is not clear, though redundancy of atrial septum could be responsible for pathogenesis of arrhythmia. ${ }^{34,37}$

Ertan Yetkin et al. ${ }^{38}$ studied the association of ASA with arrhythmias by comparing patients with ASA with a control group with non-ASA matched for age and gender. They found out that there were no differences between the groups in respect to baseline demographic, clinical parameters and echocardiographic parameters except ischemic stroke and smoking status. But there were more ASA patients significantly suffering from Atrial Premature Complex (APC), Ventricular Premature Complex (VPC), Supraventricular Tachycardia (SVT) and paroxysmal Atrial Fibrillation (AF) compared to non-ASA patients. Logistic regression analysis also showed that these parameters were independently associated with the presence of ASA. ${ }^{38}$

Morelli et al. also reported an association between atrial septal aneurysm and cardiac arrhythmias in a study involving twenty patients with atrial septal aneurysm and 19 control subjects who had 24-h Holter monitoring. ${ }^{39}$ They found frequent $(>10 / \mathrm{h})$ atrial premature beats were observed in seven patients vs. none of the controls $(P=0.008)$. The mean number of episodes of supraventricular tachycardia and the prevalence of ventricular tachycardia were also higher in the ASA group ( $\mathrm{p}=0.044$ and $\mathrm{p}=0.046$, respectively). Left atrial enlargement, mitral valve prolapse and left ventricular hypertrophy were more frequent than in the normal subjects.

In case of atrial arrhythmia, specific treatment is given depending on the type of arrhythmia. If there are thromboembolic phenomena, this is also managed accordingly. ${ }^{34}$ There are many reports which link ASA with cardiac thromboembolic stroke. ${ }^{26,40,41}$ Hanley and coworkers ${ }^{26}$ reported clinical events compatible with cardiogenic embolism in $16(20 \%)$ of 80 consecutive patients with ASA; in 4 of these patients, ASA was the only apparent cardiovascular abnormality. Belkin and coworkers ${ }^{41}$ reported cerebrovascular events compatible with embolism in $10(28 \%)$ of 36 patients with ASA. There are different theories which try to explain increased thromboembolism in patients with ASA. ${ }^{42}$ The ASA can be a direct source of thrombus formation. ${ }^{42}$ There are reports documenting thrombotic material within the aneurysmal sac in patients at autopsy or cardiac surgery and micro thrombi attached to or generated within the cul de sac of the ASA. ${ }^{43}$ It has also been noted that there are marked thickening of the atrial septum suggestive of thrombus formation in patients with ASA. ${ }^{43}$ ASA is also associated with atrial fibrillation and this may be one of the sources of intracardiac thrombosis as seen in case 2 .

ASA can also present as a case of pulmonary embolism. Estagnasié et al. ${ }^{44}$ reported three cases with refractory hypoxaemia in which echocardiography with contrast showed right to left interatrial shunting and pulmonary hypertension in keeping with pulmonary embolism. The latter was detected by an early and massive passage of contrast from the right to the left atrium.

The treatment for intracardiac thrombosis will depend on whether it is presenting in isolation or together with a PFO, an interatrial shunt or cerebrovascular events. Isolated thrombosis if diagnosed with the help of TTE will need antiplatelets. When thrombosis is accompanied with PFO with or without shunts antiplatelets are still indicated. When the shut is due to ASD then surgical repair may be required if there are circulatory abnormalities or TIAS. In the presence of repeated TIAS or cerebrovascular events then anticoagulation is indicated together with appropriate surgery. Resection of the aneurysm with a wide base, and repair of the iatrogenic atrial septal defect primarily can be done. If the base of the aneurysm is not wide, plication can be applied as an alternative. ${ }^{14}$

Patients with a patent foramen ovale associated with redundant and fenestrated atrial septal aneurysms and a history of multiple transient ischaemic episodes can have percutaneous device closure using the Atriasept $\mathrm{t}^{\mathrm{TM}}$ II septal occluders. Atriasept ${ }^{\mathrm{TM}}$ II PFO occluder is a safe and effective device for patients with multiple defects and associated ASAs. ${ }^{14}$

\section{Conclusions}

Globally, ASA is a rare cardiac abnormality that appears to be even rarer in sub-Saharan Africa. It is not known why there are few cases reported in this region but inadequate investigative equipment and expert personnel may partly explain this low prevalence. The clinical significance of ASA becomes heightened following intracardiac thrombosis and systemic and pulmonary embolism culminating in cerebrovascular events. These are events that can be prevented if the right assessment is done early. ASA can be an isolated abnormality but there may be other cardiac abnormalities notably PFO, ASD, mitral valve prolapse, mitral and tricuspid regurgitation. Echocardiography is used to diagnose ASA, either during routine echocardiography or in cases of cardioembolic cerebrovascular stroke and peripheral embolism. Trans esophageal echocardiography is more sensitive than trans thoracic echocardiography in picking up ASA. Cardiac computed tomography and magnetic resonance imaging are also useful for diagnosis of ASA. It is important that a high index of suspicion is maintained as this will lead to early diagnosis and therapy which is avaialble. Therapeutic options for prevention of recurrent strokes in patients with atrial septal aneurysm as well as atrial septal abnormality including patent foramen ovale and ostium secundum atrial septal defect, are medical therapy with antiplatelet agents or anticoagulants and surgical or percutaneous closure of the defect.

\section{References}

1. Silvestry FE, Cohen MS, Armsby LB, et al. Guidelines for the echocardiographic assessment of atrial septal defect and patent foramen ovale: from the American Society of Echocardiography and Society for Cardiac Angiography and Interventions. J Am Soc Echocardiogr 2015;28:910-58.

2. Griffin BP, Topol EJ. Manual of Cardiovascular Medicine. $3^{\circ}$ edition. Lippincott Williams and Wilkins; 2008. pp. 444.

3. Lesson P, Augustine D, Mitchell ARJ, Becher H. Transthoracic anatomy and pathology: chambers and vessels. In: Lesson P, Augustine D, Mitchell ARJ,Becher H (eds). Echocardiography (OSHs in Cardiology). 2 edition. Oxford University Press; 2012. pp. 191-341.

4. Pearson AC, Nagelhout D, Castello R, et al. Atrial septal aneurysm and stroke: a transesophageal echocardiographic study. J Am Coll Cardiol 1991;18:1223-9.

5. Gallet B, Malergue MC, Adam C, et al. Atrial septal aneurysm: a 
potential cause of systemic embolism. Br Heart J 1985;53:292297.

6. Longhini C, Brunazzi MC, Musacci G, et al. Atrial septal aneurysm: echopolycardiographic study. Am J Cardiol 1985;56:653-6.

7. Lin CS, Chen HY, Jan YI. The interatrial septal echocardiogram: relationship to left atrial volume change in the normal and diseased heart. Am Heart J 1984;107:519-25.

8. Chiappa EM, Cook AC, Botta G, Silverman NH. Echocardiographic anatomy in the fetus. Springer; 2008.

9. Necas M. Redundant septum primum flap in fetus with premature atrial contractions. OBGYN.net. April 2000. Available from: https://www.contemporaryobgyn.net/view/redundant-septumprimum-flap-fetus-premature-atrial-contractions

10. Armstrong WF, Ryan T. Contrast echocardiography. In: Armstrong WF, Ryan T (eds). Feigenbaum's Echocardiography. Wolters Kluwer; 2010. pp. 67-90.

11. Olivares-Reyes A, Chan S, Lazar E, et al. Atrial septal aneurysm: a new classification in 205 adults. J Am Soc Echocardiogr 1997; 10:644-56.

12. Tamatey MN, Sereboe LA, Tettey MM et al. Twenty-two years of repair of atrial septal defects in Ghana. Postgraduate Med J Ghana 2015;4:2.

13. Ker J. The enigma of bulging to the left-a case report of an unusual atrial septal aneurysm. J Clinic Experiment Cardiol 2012,3:2.

14. Brown S, Buys D. Percutaneous closure of patent foramen ovale and atrial septal aneurysm using the Atriasept ${ }^{\mathrm{TM}}$ II PFO occluder: clinical and technical implications. Cardiovasc J Afr 2011:22:274-7.

15. Yuko-Jowi C, Okello C. Left ventricular inflow obstruction by giant atrial septal aneurysm in a neonate with hypoplastic right heart syndrome: case report. East Afri Med J 2013;90:67-71.

16. Danbauchi SS, Alhassan SS, Oyati IA, Onyemelukwe GC. Atrial septal aneurysm in an 80 year old woman: A case report and review of literature. Ann Afr Med 2002;1:31-4.

17. Oyedeji AT, Okunola O, Sani MU. Atrial septal aneurysm mimicking a cor triatriatum sinister: a case report and review of the literature. Clin Med Insights Case Rep 2012;5:143-7.

18. Odetunde OI, Ekwochi U, Chinawa J. Conducting defect with atrial septal aneurysm in a preterm neonate: A case report from resource limited setting. Niger J Paed 2015;42:64-7.

19. Rodriguez CJ, Homma S, Sacco RL, Di Tullio MR. Race-ethnic differences in patent foramen ovale, atrial septal aneurysm, and right atrial anatomy among ischemic stroke patients. Stroke 2003;34:2097-102.

20. Salmasi AM, Salmasi H, Rawilins S, et al. Atrial septal aneurysm and patent foramen ovale are less prevalent in the Indo-Asian than in the Caucasian or Afro-Caribbean population. Angiology 2009;61:205-10.

21. Silver MD, Dorsey JS. Aneurysms of the septum primum in adults. Arch Pathol Lab Med 1978; 102:62-5.

22. Brand A, Keren A, Branski D, et al. Natural course of atrial septal aneurys $\mathrm{m}$ in children and the potential for spontaneous closure of associated septal defects. Am J Cardiol 1989;64:996-1001.

23. Mügge A, Daniel WG, Angermann C, et al. Atrial septal aneurysm in adult patients. A multicenter study using transthoracic and transesophageal echocardiography. Circulation 1995;91:2785-92.

24. Falanga G, Carerj S, Oreto G, et al. How to understand patent foramen ovale clinical significance, Part I. J Cardiovasc Echogr
2014;24:114-21.

25. Snijder RJ, Luermans JG, de Heij AH, et al. Patent foramen ovale with atrial septal aneurysm is strongly associated with migraine with aura: A large observational study. J Am Heart Assoc 2016;5:e003771.

26. Hanley PC, Tajik AJ, Hynes JK, et al. Diagnosis and classification of atrial septal aneurysm by two-dimensional echocardiography: report of 80 consecutive cases. J Am Coll Cardiol 1985;6:1370-82.

27. Iliceto S, Papa A, Sorino M, Rizzon P. Combined atrial septal aneurysm and mitral valve prol apse: detection by two-dimensional echocardiography. Am J Cardiol 1984;54:1151-4.

28. Roberts WC. Aneurysm (redundancy) of the atrial septum (fossa ovale membrane) and prola pse (redundancy) of the mitral valve. Am J Cardiol 1984;54:1153-4.

29. Iliceto S, Papa A, Sorino M, Rizzon P. Combined atrial septal aneurysm and mitral valve prolapse: detection by two-dimensional echocardiography. Am J Cardiol 1984;54:1151-4.

30. Rahko PS, Xu QB. Increased prevalence of atrial septal aneurysm in mitral valve prolapse. Am J Cardiol 1990;66:253-7.

31. Werren M. Clinical implications of familial occurrence of atrial septal aneurysm. G Ital Cardiol 2008;9:579-82.

32. Yetkin E, Atalay H, Ileri M. Atrial septal aneurysm: prevalence and covariates in adults. Int J Cardiol 2016;223:656-9.

33. Jatav RK, Kumbhare MB, Surender T, et al. Atrial septal aneurysm in adult patients: spectrum of clinical, echocardiographic presentation and to propose a new classification on the basis of trans-thoracic-two-dimensional echocardiography. Int J Res Med Sci 2014;2:708-17.

34. Shah MD. A look at atrial septal aneurysm. e-J Cardiol Pract 2012;10:17.

35. Homma S, Sacco RL, Di Tullio MR, Sciacca RR, Mohr JP. Atrial anatomy in non-cardioembolic stroke patients: effect of medical therapy. J Am Coll Cardiol 2003;42:1066-72.

36. Wahl A, Krumsdorf U, Meier B, et al. Transcatheter treatment of atrial septal aneurysm associated with patent foramen ovale for prevention of recurrent paradoxical embolism in high-risk patients. J Am Coll Cardiol 2005;45:377-80.

37. Schneider B, Hofmann T, Meinertz T. Atrial septal aneurysm: is there an association between arrhythmias and stroke? Circulation 1993;88:222.

38. Yetkin E, Ileri M, Korkmaz A, Ozturk S. Association between atrial septal aneurysm and arrhythmias. Scand Cardiovasc J 2019:54:169-73.

39. Morelli S, Voci P, Morabito G, et al. Atrial septal aneurysm and cardiac arrythmias. Int J Cardiol 1995:49:3.

40. Gallet B, Malergue MC, Adam C, et al. Atrial septal aneurysm: a potential cause of systemic embolism. Br Heart J 1985;53:292-7.

41. Belkin RN, Hurwitz BJ, Kisslo J. Atrial septal aneurysm: association with cerebrovascular an d peripheral embolic events. Stroke 1987; 18:856-62.

42. Adauy JV, Gabrielli L, Cordava S, et al. Big thrombus "sitting" in an atrial septal aneurysm. Echocardiography 2017;34:1396-8.

43. Zabalgoitia M, Norris LP, Garcia M. Atrial septal aneurysm as a potential source of neurological ischemic events. Am J Card Imaging 1994;8:39-44

44. Estagnasié P, Djedaïhi K, Le Bourdellès G, et al. Atrial septal aneurysm plus a patent foramen ovale: a predisposing factor for paradoxical embolism and refractory hypoxemia during pulmonary embolism. Chest 1996;110:846-848. 